difficult to pass such a clinically based examination without recent experience in a training post.

Sheila A. ManN, Chief Examiner

Fiona CaldicotT, Dean

\section{A register of Munchausen cases}

DeAr Sirs

Lovestone employs several arguments against the use of a national register for psychiatric Munchausen cases (Psychiatric Bulletin, September 1991, 15, 581). The most cogent of these is that such a register might constitute a breach of confidentiality. In order to protect confidentiality the register would need to be accessible only to medical staff.

It was suggested that the use of a register is unnecessary for the diagnosis of Munchausen's syndrome. In the case I described (Psychiatric Bulletin, March 1991, 15, 167) the diagnosis was considerably facilitated by referring to a Social Services list of "hospital hoppers". More recently I have encountered a case of an aggressive and suicidal man, apparently aged 14 , who described a variety of psychiatric symptoms and who gave a history of having received depixol injections. He refused to give his home address. After admission to an adult psychiatric ward followed by a local authority children's home, he is now in a Social Services Secure Unit. It is still unclear whether he has given his true name and age and whether his psychiatric symptoms are genuine.

The assertion that making a diagnosis of Munchausen's syndrome is not helpful since there is no known treatment is surprising. Surely the recognition and documentation of a poorly understood syndrome is a pre-requisite for research into treatment and outcome. Any such research would be facilitated by a national register of cases.

Although Lovestone dismisses the economic benefits of a register these are nonetheless important both in hospitals and in local authority children's homes where there is considerable pressure on bed space. Hospital admission is not only costly but potentially harmful. Repeated admission is likely to reinforce the hospital "addiction" and may be associated with the administration of psychotropic medication which is not without its harmful effects.

My interest in a register is not the result of a fear of being "conned". I do not suffer from an overwhelming urge to consult a register when dealing with patients presenting with somatisation disorders, dissociative disorders or deliberate self-harm. It is the role of the psychiatrist to look beyond the presenting signs and symptoms to the underlying distress and personal dilemma of the patient.

Clatterbridge Hospital

R. I. DAVEY

Bebington, Wirral

Merseyside L63 4JY

\section{Use of the Mental Health Act 1983}

\section{DeAR Sirs}

I read with some disquiet the letter from Dr Azounye (Psychiatric Bulletin, July 1991, 15, 455) concerning use of the Mental Health Act 1983. I am extremely uncomfortable with the idea that legislation which has been framed to protect the civil liberties of psychiatric patients should be modified to "make life considerably easier" for psychiatrists and social workers.

Section 3 of the Act contains a very important safeguard for the patients, providing for consultation with the nearest relative. This allows the patient and his family more say in the process of compulsory admission. By admitting someone on a Section 2 this is negated. It is perfectly possible to discharge a patient from Section 3 in less than 28 days, should the patient's clinical condition dictate this.

Section 2 is framed to allow detention under less rigorous conditions in a situation in which the patient is less well known by the clinical team. Where the clinical team has extensive knowledge of the patient and, conversely, the patient and his family have knowledge of the benefits accruing from previous psychiatric treatment, then it seems essential that increased safeguards continue to apply. This view would appear to be endorsed by the Code of Practice (1990), paragraph 5.4 which states that decisions should not be influenced by the duration of proposed treatment.

In addition, where a patient is well known to services, should not the treatment plan be formulated while the patient is in the community and offered without recourse to hospital admission?

\section{Reaside Clinic}

JON KENNEDY

\section{Bristol Road South}

Rubery, Rednol

Birmingham B45 9BE

\section{Reference}

Department of Health and Welsh Office (1990) Code of Practice, Mental Health Act 1983. London: HMSO.

\section{Impact of the White Paper on Specialist Services: the Cassel Hospital Survey of Referrers}

\section{Dear Sirs}

Dolan \& Norton's findings on clinicians' views about the changes in usage of specialist services such as the Henderson Hospital (Psychiatric Bulletin, July 1991, 15, 402-404) are confirmed in part by the results of the Cassel Hospital Survey of Referrers. The Cassel Hospital has a slightly different remit to 
the Henderson, in providing a full out-patient psychotherapy service locally, as well as a national service for in-patient therapeutic community treatment with individual psychoanalytic psychotherapy, and the only in-patient family therapy unit in the country. The survey confirms this split between the hospital's role as a local out-patient psychotherapy recourse for GPs in the area (64\% GP referrers identifying this as the most useful service); and as national tertiary referral centre for consultant psychiatrists and psychotherapists in locations as far apart as the north of Scotland and the Isle of Wight (95\% of referrer psychiatrists thought the in-patient services were the most useful).

The questionnaire was sent out to referrers in the previous year in the summer of 1990 , along with a letter explaining that the survey was to gain some view of the change in demand for the service following the internal NHS changes. Of the 135 respondents, $41 \%$ were psychiatrists, $37 \%$ general practitioners, $22 \%$ other categories, including psychologists, social workers and lay psychotherapists. In the sample, $63 \%$ said that they would continue to use the services in the internal market, $4.5 \%$ said they would not, and $32 \%$ were undecided. Encouragingly, there was a willingness to put pressure on managers to fund treatment that was thought clinically appropriate, with $74 \%$ saying they would do this, $3 \%$ saying they would not, and $31 \%$ being undecided. These figures were relatively stable over the different professional groups.

One aspect of the responses to the questionnaire was a sense of camaraderie among clinicians, perhaps due to there being a necessity to struggle for clinical autonomy within the new perspective of financial restraint. This may have led to an unacceptable bias had a question about satisfaction with the service as a whole been included. Instead, respondents were asked to criticise the service, and comment on ways that it could be improved. The most common comment was about resources, with the suggestion that the service should be expanded with more places available in ongoing therapy and shorter waiting lists (mentioned 78 times in completed questionnaires). Many suggested that communication of information to the referrer could be improved, and that the service could be more "user friendly" (mentioned 23 times). Several respondents suggested that treatment priorities should be changed, for example GPs advocating more outpatient work, and one psychiatrist arguing a case for priority for patients under the auspices of the Mental Welfare Commission. Many commented that the hospital should publicise itself more actively, by producing and circulating a brochure or newsletter about services offered (45 respondents), or be more active in research and publication and presentation (12 respondents). Some suggested that the hospital should expand its teaching and supervisory role, by organising Balint type groups for local GPs, and becoming involved in local GP vocational and psychiatric training schemes.

It remains to be seen how the changes in the health service will affect the whole spectrum of psychiatric care, not only the more labour intensive specialities. We in the psychotherapy services believe that treatment of neurotic and personality disordered patients enables them to develop a lifestyle that much reduces the need for repeated crisis admissions, which in the long run represents a considerable saving for health boards. The anxiety is that short-term financial considerations by managers may obscure this, and alter the clinically appropriate care of patients. There appears to be healthy resistance to this, among referrers from all groups in this study.

JOHN DENFORD

KeVIn Healey

The Cassel Hospital

MARK G. A. MORRIS

1 Ham Common

Richmond, Surrey

TW10 7JF

\section{Working with clozapine}

\section{Dear Sirs}

C. Adams and M. A. Essali have provided a timely and informative outline on the benefits of clozapine treatment in resistant schizophrenic patients (Psychiatric Bulletin, June 1991, 15, 336-338). With regard to the risk of agranulocytosis, it may be worth noting that clinical judgement can be suspended often in the best interest of the patient when a little reflection might clarify the problem. I would like to report on one such case.

A 19-year-old unemployed male with treatmentresistant schizophrenia since the age of 13 had several admissions to hospital. Different antipsychotic regimes in large doses were prescribed without satisfactory relief of symptoms. Clozapine was commenced in July 1990, two days later he developed pyrexia, sore throat and headache. His WBC and neutrophils dropped sharply. Clozapine was stopped immediately. Next day he developed a maculopapular rash on arms and chest. Chickenpox was diagnosed. The reason for the drop in WBCs and neutrophils became apparent and he was restarted on clozapine 12 days later. Response to medication was good in a matter of days. He became symptom free. He has been on medication for about 11 months. Monotherapy has been achieved and no readmission since clozapine was commenced.

\author{
Worcester Royal Infirmary \\ Newtown Branch, Newtown Road \\ Worcester WRS $1 J G$
}

Ahmad Mahmood 